\title{
THE CHALLENGES OF OPEN DATA MOVEMENT FOR EDUCATION: WHAT IS THE SAY OF YOUNG EMPLOYEES AND STUDENTS IN CROATIA?
}

\author{
Branka Mraović, Faculty of Geodesy, University of Zagreb, Croatia
}

\section{Abstract}

This paper aims to shed light on how students and young employees in Croatia assess their education for open data and what is their opinion on the compliance of the central Open Data Portal with the needs of young people as well as how they evaluate open data policy related to the young people in Croatia. This research highlights the lack of technical knowledge as a serious obstacle to the productive use of open data. As many as $56 \%$ of respondents from companies that have undergone digital transformation believe that they do not have enough knowledge to participate in open data projects, and the same scepticism is expressed by $59.6 \%$ of non-technical respondents and $45.7 \%$ of students. The data presented in this paper is part of a broader empirical research on the impact of digitalization on the transformation of the Croatian economy, carried out by the author in late 2018 on a sample of 51 young employees from 10 companies in the city of Zagreb and 70 students from 16 technical and non-technical Faculties of Zagreb University.

\section{Introduction}

In this paper, on the example of the reception of the Open Data movement among the young population in Croatia, I want to draw attention to the importance of the proactive role of the education system and its obligation to provide students with action knowledge that will enable them to successfully cope with the challenges of rapid development of high-tech environment. I want to emphasize that education is primarily a cultural phenomenon that should: (a) serve the welfare of society and man; (b) promote the values of cooperation and altruism, and (c) be organized so as to strive for the common good. Under the influence of digitalization, the role of users is changing. In earlier stages of internet development, they were consumers of e-content, and technological development enabled them to convert to e-content creators. The development of advanced technologies, especially 2.0 (social media), Web 3.0 (semantic web), and web 4.0 (Internet of Things IoT) opens up huge opportunities for governments, companies, institutions and citizens, 
Mraović, $B$.

The Challenges of Open Data Movement for Education: What is the Say of Young Employees and Students in Croatia?

but also sets new educational demands before them. New technologically mediated forms of learning are at work that require new knowledge and skills. This primarily refers to knowledge of search techniques, knowledge of digital media and data literacy. However, in order to turn the potentials provided by the non-human entities into real benefits for the humans, new mental models of people are needed, with education systems and academic community expected to play a key role in these radical transformations of our lives, work and ways of thinking. The focus of this analysis is how students and young employees perceive open data policy in Croatia, and how they assess their educational readiness for open data.

\section{E-Government and Open Data}

In a complex, dynamic and interdependent global community, no one can function as a lonely island, not even the governments. As Schellong (2010) points out, the development of Web 2.0 has changed the understanding of the role of Government and the way it works. "The term Government 2.0 refers to the use of social software and underlying philosophy of Web 2.0, information sharing, transparency or peer production in government" (Schellong, 2010; p.374). Electronic Government (e-Government) or "Open Government" (Obama Administration, Office of Management Budget, 2008; the Malmoe Declaration, European Commission, 2009) or "Government 2.0" is networking Government. The dominant trend of a data-driven society is the constant democratization of data use and protection, in which the European Union regulatory framework takes the lead. Consequently, citizens are perceived as co-creators in policy-making, public management and public service delivery (Schellong, 2010). In the new millennium, the governments around the world are making efforts to develop the open data ecosystems with the goal of using open data to create new value in the business sector. The term "open data of public administration" refers to an information policy that provides a set of management principles aimed at promoting the sharing and reuse data sets that does not restrict privacy and confidentiality, which are produced with public money and are available without restrictions on their use and distribution (Styrin, Luna-Reyes, \& Harrison, 2017; pp.132-3). The goal of the open data policy promoted by large international and supranational organizations such as the UN, World Bank, OECD, EU and others is to create a business climate with the aim of improving services and motivating users to be creative and develop new innovative companies. Open data is considered to be one of the key factors that will enable the transformation of public administration and the development of the digital economy. Empirical research by Zhao, Wallis, and Singh (2015) indicated a strong positive reciprocal link between the development of e-government and the digital economy. It also confirmed that the co-evolution between technology and organization continues in the 
Mraović, B.

The Challenges of Open Data Movement for Education: What is the Say of Young Employees and Students in Croatia?

context of the $4^{\text {th }}$ Industrial Revolution and pointed to the importance of national cultural features for the digital transformation of the economy, state and society.

Croatia became a full member of the EU in July 2013 and has since started the process of translating open data policy into the Croatian context. At its $107^{\text {th }}$ session on 19 July 2018, the Government of the Republic of Croatia adopted the Open Data Policy, which represents a strategic direction for further development of the policy of openness and transparency of public administration, whose implementation aims to create and develop an enabling environment for the opening up and re-use of public authority data to create a new social and economic value. According to EU estimates, the open data market in 2020 would amount to at least 75.7 billion euros and open the possibility of new employment for 25,000 people. For the Republic of Croatia, the EU estimated the creation of up to 1,000 new jobs in 2020, and the market value was estimated at EUR 186 million (Government, HR, 2018).

\section{Promoting Open Data, Enabling Proactive Learners}

From the conceptual project of digitalization emerges the concept of a Big Society which is realized through a human-machine symbiosis in a wide range of collaborative projects between the corporate and public sector and the academic community. Ekbia et al. (2015) use a term "heteromation" as the term to indicate the new creative role of people in creating the knowledge infrastructure in a high-tech environment and emphasize the "distinction between data generated by people versus data generated about people". This opens up the possibility for individuals and small players to "own" their data and that through shared participation in data collection they are no longer just measured, but also the "measuring subjects". To reduce costs, an increasing number of companies (Amazon, Tesla) and institutions (NASA) use volunteer computing to test software and solve specific algorithmic problems. Through the spread and popularity of open linked data, an increasing number of authors are contributing to the extraction of web data into a semantic web format (Fang, Sheng, Wang, Ngu, \& Zhang, 2017; p.121). The idea that is particularly promoted by academic knowledge bases such as Freebase, DBpedia and DeepDive is to enable as many people and machines as possible to share jointly generated knowledge.

The penetration of advanced technologies into all spheres of people's lives, work and thinking, and their universal, pervasive and radical character, poses numerous questions, dilemmas and challenges to engineering professions, scientists, education systems, citizens and politicians. But at the same time, technology affirms the values of civil society and supports the rights of citizens, and expands the influence of local communities. However, as Haraway (2007) categorically argues, every vision implies in itself the power to see and the point of view of interest, and consequently, requires responsibility. 
Mraović, $B$.

The Challenges of Open Data Movement for Education: What is the Say of Young Employees and Students in Croatia?

"Technologies are skilled practices. How to see? Where to see from? What limits to vision? What to see for? Whom to see with? Who gets to have more than one point of view? Who gets blinkened? Who wears blinkers? Who interprets the visual field? What other sensory powers do we wish to cultivate besides vision?" (Haraway, 2007; p.120).

Situated knowledge develops from communities, not from isolated individuals, through "decoding" and transcoding plus translation and criticism (Haraway, 2007; p.122), leading to affirmation of partiality, and not universality, which allows the "knowledge of subjugated" to be involved in the paradigmatic model of science. This knowledge can be an important and useful guideline for strategic thinking that facilitates both moving in the desired direction and avoiding undesirable outcomes. Her plea for situated and embodied knowledge aims at "transformation of systems of knowledge and ways of seeing", as being convinced that transformative potentials of knowledge can lead to the organization of the world that will be less dependent on the will to dominate.

National digital strategies around the world recognize open data as a conditio sine qua non and as one of the key tools that enable productive, participatory and innovative interactions between citizens and public servants, by expanding the space of experimentation to find new solutions to new problems opened by the development of disruptive technologies in various spheres of the business sector, education, health, culture and politics. The OECD study (2016) as the two main challenges for the open data policy emphasizes the "resistance to publish open data and the lack of human resources with technical training to effectively participate in the process of opening data" (Styrin, Luna-Reyes, \& Harrison, 2017; p.146).

Research by Styrin, Luna-Reyes, and Harrison (2017) highlights that the national open data projects depend on political leadership and the involvement of multiple stakeholders such as civil servants, IT developers, entrepreneurs, data activists from NGOs, IT industry, citizens and financial institutions. They identified political leadership as the most vulnerable aspect because it can change periodically with elections. This indicates to the need to cultivate an organizational culture and a positive climate towards open data, for which the USA is a successful example. Cordella and Hesse (2014) point to stakeholder theory as a useful tool for analysing the impact of open data ecosystems on the scope and pace of digital transformation of the state. The authors give an example of the use of ANT as a useful analytical lens to measure the dynamics of e-government projects because they imply the connection and interaction of different actors in complex negotiation processes. Research by Pinochet et al. (2019) sheds light on open data as a new form of activism leading to a collective intelligence that will enable greater transparency of public activities. 
Mraović, $B$.

The Challenges of Open Data Movement for Education: What is the Say of Young Employees and Students in Croatia?

They point to young people as an important social group that will play a crucial role in promoting digital education.

\section{Results of the empirical research and data analysis}

\section{Research goals}

This article presents the data on how students and young employees in Croatia assess their education for open data projects, and what is their opinion on the compliance of the central Open Data Portal with the needs of the Young as well as how they evaluate open data policy related to the young people in Croatia.

\section{Sample of respondents}

The author conducted this study late in 2018 on a sample of 51 young employees aged to 35 from 10 companies in the area of the city of Zagreb that use new technologies and work with large datasets and 70 students aged to 25 from 16 technical and non-technical Faculties of Zagreb University. In the group of employees, the sample included respondents from: pure digital companies, companies that have undergone digital transformation and geospatial institutions; small, large and medium-sized companies; public and private; from 10 industry branches (e-commerce, Internet advertisement, University Computing Center, distribution and logistics, energetics, telecommunications, National roads, gas industry, Cadastre Zagreb and Land Registry Law Office).

\section{Hypotheses}

In accordance with the formulated goals, the following hypotheses were formulated:

- I expect that there is the probability of relationships between occupation, type of education and level of digitalization of the company and respondents' opinion of their educational readiness for open data projects, and I expect that the observed groups of respondents will differ in measured characteristics.

- I expect that the observed groups of respondents will differ in their views on the compliance of the central Open Data Portal with the needs of the Young, and the way in which they perceive open data policy for the Young

\section{Variables}

The pivotal independent variables (predictors) in this article are occupation (students and young employees), a type of education (technical and non-technical), and the level of digitalization of the company (pure digital, companies that have undergone digital transformation, and geospatial institutions). Measured dependent variables are: selfevaluations of the respondent's educational readiness for open data, attitudes towards the 
Mraović, $B$.

The Challenges of Open Data Movement for Education: What is the Say of Young Employees and Students in Croatia?

work of the central Open Data Portal, attitudes towards open data policy, and perceptions of the most deserving actors for data opening in Croatia.

\section{Methods of data processing}

Inferential analysis was done in R statistical package (R Core Team, 2020), while dataset preparation and figures were done in Stata statistical software, version 14.2 (StataCorp, 2015). The data were processed using a hi-square test.

\section{Data analysis}

\section{Self-evaluation of students and young employees of their educational readiness for open data}

The finding obtained showed that students and young employees similarly perceive the level of their education in the field of technical sciences for open data, namely $49 \%$ of employees and $32.9 \%$ of students believe that they are educated enough to be able to set specific data requirements that will be useful to them $\left(X^{2}=4.5, d f=2, p<0.106\right)$.

The data show that technical and non-technical respondents differ statistically significantly in their opinion on the sufficiency of their education for open data requirements $\left(\mathrm{X}^{2}=12.4, \mathrm{df}=2, \mathrm{p}<0.002\right)$. Also, respondents from pure digital companies, transformed companies and geospatial companies differ statistically significantly regarding this measured variable $\left(\mathrm{X}^{2}=16.2, \mathrm{df}=4, \mathrm{p}<0.003\right)$. It is worth noting that as many as $90 \%$ of respondents from geospatial companies compared to $62.5 \%$ from pure digital and $24 \%$ from transformed companies perceive their technical education sufficient for open data (Figure 1).

The high evaluation that respondents from geospatial institutions attribute to their education can be explained by the fact that the sector has been involved for many years in coordinated activities at the global (UN), regional (EU) and national state level aimed at building the Global Spatial Data Infrastructure, and this is also linked to continuing education programs for the Staff (after the EU INSPIRE Directive entered into force on 15 May 2007). This finding confirms some other analyses according to which spatial data are one of the best developed areas in the field of open data in Croatia. On the other hand, the critical attitude of respondents from pure digital companies could be due to the high complexity of the work environment and the rapid changes in the ways of performing work operations imposed by the ICTs development. It is certainly alarming to find that among those respondents who feel that their technical education is not sufficient for active involvement in data-opening processes and their effective use, there are:

- $41.2 \%$ of employees and $45.7 \%$ of students;

- $59.6 \%$ of non-technical and $29.7 \%$ of technical respondents; 
Mraović, $B$.

The Challenges of Open Data Movement for Education: What is the Say of Young Employees and Students in Croatia?

- $\quad 56 \%$ of respondents from transformed, $37.5 \%$ from pure digital companies and $10 \%$ from geospatial institutions.

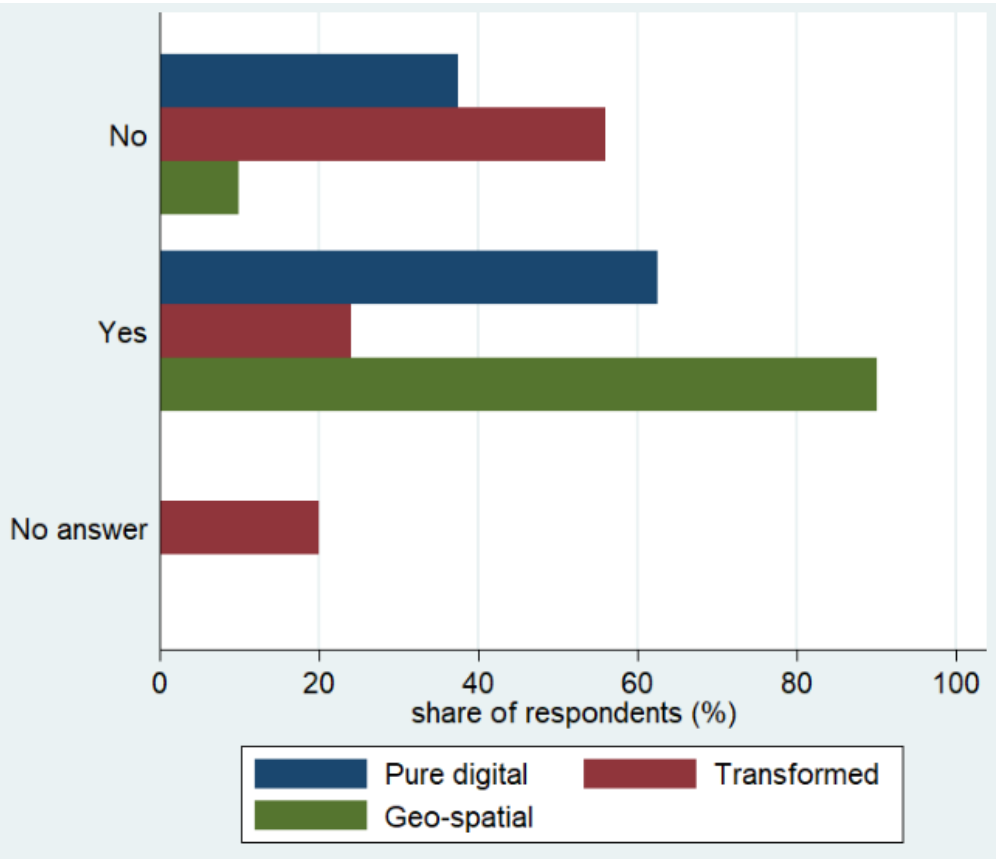

Figure 1. Perceptions of sufficiency of education for setting open data demands

\section{Attitudes of students and young employees about open data policy in Croatia}

One of the goals of this research is to shed light on how young respondents peive open data policy in Croatia. I operationalized this research question through three close-ended questions: (a) Is the central Open Data Portal (data.gov.hr) sufficiently adapted to young people?; (b) How would you assess the results of the open data policy in Croatia related to the Young so far?; (c) How would you assess the contributions of key stakeholders engaged in data opening in Croatia in terms of promoting user participation: Government; Nongovernmental organizations; IT industry; Innovators; Entrepreneurs; Financial institutions; Politicians; Someone else, who. The finding obtained confirmed the initial hypothesis as it shows that the occupation, type of education and level of digitalization of the company have a significant impact on the way respondents assess open data policy in Croatia.

The data show that students and young employees differ statistically significantly in terms of their perception of the adaptation of the central Open Data Portal to young people $\left(\mathrm{X}^{2}=22.5, \mathrm{df}=3, \mathrm{p}<0.001\right)$. Statistically significant differences regarding the perception of the adaptation of the central Open Data Portal to young people also exist between respondents with technical and non-technical type of education $\left(X^{2}=9.5, \mathrm{df}=3\right.$, $\mathrm{p}<0.023)$, and between respondents from pure digital and transformed companies and geospatial institutions $\left(\mathrm{X}^{2}=23.6, \mathrm{df}=4, \mathrm{p}<0.001\right)$. 
Mraović, $B$.

The Challenges of Open Data Movement for Education: What is the Say of Young Employees and Students in Croatia?

The central Open Data Portal is sufficiently adapted to young people according the opinion of:

- $\quad 29.4 \%$ of employees and $7.1 \%$ of students;

- $20.3 \%$ technical and $12.3 \%$ non-echnical respondents;

- $\quad 90 \%$ respondents from geospatial institutions, $25 \%$ from pure digital companies and only $8 \%$ from transformed companies.

The open data policy for young people in Croatia is considered satisfactory by:

- $\quad 19.6 \%$ of employees and $5.7 \%$ of students;

- $12.5 \%$ of technical and $10.5 \%$ of non-technical respondents;

- $60 \%$ of respondents from geospatial institutions, $12.5 \%$ from pure digital companies and only $8 \%$ from transformed companies.

According to frequencies' orderings, as stakeholders who have given the greatest contributions to the opening of data in Croatia in terms of promoting the participation of users, students identify: (a) IT industry (81.7\%), (b) innovators (73.3\%), and entrepreneurs (65\%), while young employees first place entrepreneurs (82.6\%), then the IT industry (80.4\%), and financial institutions (69.6\%).

\section{How familiar are young employees and students with the open data policy in Croatia?}

What concerns in particular is the poor awareness of the young population on open data policy in Croatia. Among those respondents who are not familiar with the activities of the central Open Data Portal (data.gov.hr) are:

- $\quad 54.3 \%$ of students and $39.2 \%$ of employees;

- $\quad 56.1 \%$ of non-technical and $40.6 \%$ of technical respondents;

- $52 \%$ respondents from transformed companies, $43.8 \%$ from pure digital companies and $0.0 \%$ from geospatial institutions.

Among those respondents who are not familiar with the Open Data policy for the Young in Croatia are:

- $\quad 55.7 \%$ of students and $51 \%$ of employees;

- $\quad 54.4 \%$ of non-technical and $53.1 \%$ of technical respondents;

- $72 \%$ of respondents from transformed companies, $50 \%$ from pure digital companies and $0.0 \%$ from geospatial institutions. 
Mraović, $B$.

The Challenges of Open Data Movement for Education: What is the Say of Young Employees and Students in Croatia?

\section{Conclusions}

Respondents from geospatial institutions have the most positive perception of open data policy in Croatia, while respondents from transformed companies are the most critical of it. Respondents from geospatial institutions believe that they are sufficiently educated for open data (90\%), believe that the Central Open Data Portal is sufficiently adapted to the young people (90\%) and that Croatia has a good open data policy for the young people $(60 \%)$. This research highlights the lack of technical knowledge as a serious obstacle to the productive use of open data. As many as $56 \%$ of respondents from transformed companies believe that they do not have enough knowledge to participate in open data projects, and the same scepticism is expressed by $59.6 \%$ of non-technical respondents and $45.7 \%$ of students. As stakeholders who have made the greatest contributions to the opening of data in Croatia in terms of promoting user participation, students identify: (a) IT industry (81.7\%), (b) innovators (73.3\%) and entrepreneurs (65\%), while young employees put entrepreneurs first (82.6\%), followed by the IT industry (80.4\%) and financial institutions (69.6\%). What concerns in particular is the poor awareness of the young population on open data policy in Croatia. As many as $55.7 \%$ of students, $72 \%$ of respondents from transformed companies and 50\% from pure digital companies are not familiar with the open data policy, while the level of information of respondents from geospatial institutions is $100 \%$. To embrace artificial intelligence, users need to be helped to understand and love it, and in these intentions, the online learning movement is and can be a motivating leader. Although this is a small sample, the results of this research can undoubtedly be a useful message to the education system and curriculum creators, but also to the media content editors.

\section{References}

Cordella, A., \& Hesse, J. (2015). E-government in the making: an actor network perspective. Transforming Government: People, Process and Policy, 9(1), 104-125. doi:10.1108/TG-02-2014-0006

Ekbia, H., Mattioli, M., Kouper, I., G. Arave, G., Ghazinejad, A., Bowman,T., Ratandeep Suri, V., Tsou, A., Scott Weingart, S., \& Sugimoto, C.R. (2015). Big data, bigger dilemmas: A critical review. Journal of the Association for Information Science \& Technology, 66(8), 1523-1545.

Fang, X. S., Sheng, Q. Z., Wang, X., Ngu, A. H. H., \& Zhang, Y. (2017). GrandBase: generating actionable knowledge from big data. PSU Research Review, 1(2), 105-126. https://doi.org/10.1108/PRR-01-2017-0005

Haraway, D. (2007). Situated knowledge. In K. Asdal, B. Brenna , \& I. Moser (Eds.), Technoscience, The Politics of Interventions (pp. 109-134). Oslo: Academic Press. 
Mraović, $B$.

The Challenges of Open Data Movement for Education: What is the Say of Young Employees and Students in Croatia?

Mulholland, J. (2016, September 27). What Obama Did for Tech: Transparency and Open Data. Government Technology [Blog post]. Retrieved from https://www.govtech.com/data/What-Obama-Did-for-Tech-Transparency-and-OpenData.html

R Core Team (2020). R: A language and environment for statistical computing. R Foundation for Statistical Computing, Vienna, Austria. Retrieved from https://www.R-project.org

Schellong, A. R. M. (2010). Bencmarking EU e-government at the crossroads. A framework for e-government benchmark design and improvement. Transforming Government: People, Process and Policy, 4(4), 365-385. doi 10.1108/17506161011081336

StataCorp (2015). Stata Statistical Software: Release 14. College Station, TX (USA): StataCorp LP.

Styrin, E., Luna-Reyes, L. F., \& M. Harrison, M. T. (2017). Open data ecosystems: an international comparison. Transforming Government: People, Process and Policy, 11(1), 132-156. https://doi.org/10.1108/TG-01-2017-0006

Vlada Republike Hrvatske (2018). Politika otvorenih podataka, srpanj 2018. Retrieved from https://rdd.gov.hr/UserDocsImages/SDURDDdokumenti/POLITIKA\%20OTVORENIH\%20PODATAKA.pdf

Zhao, F., Wallis, J., \& Singh, M. (2015). E-government development and the digital economy: a reciprocal relationship. Internet Research, 25(5), 734-766. doi:10.1108/IntR-02-2014-0055

\section{Acknowledgements}

I thank my colleague Marko Lucić for processing this data, commitment and enthusiasm. 